\title{
MONITORAMENTO DE PARÂMETROS FÍSICOS, QUÍMICOS E BIOLÓGICOS EM UM REATOR ANAERÓBIO HÍBRIDO (RAH) EM ESCALA PILOTO, TRATANDO ÁGUA RESIDUÁRIA DO CAFÉ PRODUZIDO POR VIA ÚMIDA
}

\author{
Monitoring of physical, chemical, and biological parameters of a hibrid anaerobic \\ reactor (HAR) in pilot scale, treating wastewater from wet coffee production
}

\author{
Vivian Galdino da Silva ${ }^{1}$, Claudio Milton Montenegro Campos ${ }^{2}$, \\ Júlia Ferreira da Silva ${ }^{3}$, Priscila Helena Almeida ${ }^{4}$, Minella Alves Martins ${ }^{5}$
}

\begin{abstract}
RESUMO
Conduziu-se este trabalho, com o objetivo de fornecer informações a respeito da investigação experimental realizada na estação piloto no Núcleo de Estudos em Cafeicultura (NECAF/UFLA), para tratamento de água residuária do café (ARC) especificamente, o monitoramento de um Reator Anaeróbio Híbrido (RAH), utilizando minifiltros preenchidos com dois tipos de meio suporte (argila expandida e seixo rolado). O RAH possuía fundo falso e foi utilizado como inóculo lodo anaeróbio de Upflow anaerobic sludge blanket reator (reator anaeróbio de manta de lodo) - UASB (escala-plena), de esgoto doméstico. O sistema foi monitorado por meio de parâmetros operacionais e de análises químicas e físico-químicas. Foi constatado que a fase experimental em que se deu o experimento dificultou a eficiência do RAH por ter sido submetido a cargas inferiores às previstas, uma vez que o efluente passava por tratamento em outras unidades, minimizando assim, a concentração orgânica a ser tratada. O RAH apresentou concentrações afluentes médias de: 484; 168 e $92 \mathrm{mg}$ DQO $\mathrm{L}^{-1}$ e concentrações efluentes médias de 344; 159 e $90 \mathrm{mg}$ DQO $\mathrm{L}^{-1}$, para os tempos de detenção hidráulica (TDH) de 28,5; 23,7 e 18,0 horas, respectivamente. O RAH apresentou equilíbrio com relação aos parâmetros medidos e boa estabilidade. O efluente analisado não apresentou riscos de salinidade, uma vez que a CE ficou na faixa, entre 0,70 e 3,0 dS m ${ }^{-1}$ e os SDT, entre 450 a $2000 \mathrm{mg} \mathrm{L}^{-1}$. Quanto à sodificação, a Razão de Adsorção de Sódio (RAS) ficou entre 0 e 3 e a CE>0,7 dS $\mathrm{m}^{-1}$, podendo ser reutilizado para irrigação da maioria das culturas e solos.
\end{abstract}

Termos para indexação: Minifiltros, argila expandida, salinidade, reutilização.

\section{ABSTRACT}

The purpose of this work is to supply information regarding to the experimental investigation carried out in a pilot scale system, located at Coffee Study Research Center (NECAF/UFLA). The research focused mainly on a Hybrid Anaerobic Reactor (HAR) operating with mini-filters filled with two types of physical support (expanded clay and pebble "round quartz stone"). The HAR used a three-phase-separator; and during the start-up, sludge from a full-scale UASB reactor treating domestic wastewater was utilized. The experimental results did not show great efficiency due to the removal of the organic matter in other treatment units located before the HAR, minimizing in this way the concentration of organic matter to be treated in the HAR. The HAR presented an average affluent concentration of: 484,168 , and $92 \mathrm{mg} \mathrm{COD}_{\text {to }} \mathrm{L}^{-1}$, and an average effluent concentration of: 344,159 , and $90 \mathrm{mg}$ $\mathrm{COD}_{\text {tot }} \mathrm{L}^{-1}$. The HAR also presented good balance in relation to the parameters measured, as well as good stability.

Index terms: Mini-filters, expanded clay, salinity, wastewater reuse.

(Recebido em 29 de janeiro de 2008 e aprovado em 8 de outubro de 2008)

\section{INTRODUÇÃO}

A cafeicultura, em particular, é geradora de diversos tipos de resíduos e subprodutos. Uma grande quantidade de água é usada nas atividades de lavagem e descascamento de frutos, principalmente se o beneficiamento for feito por via úmida. A água de lavagem é rica em material orgânico e inorgânico e não deve, de modo algum, ser lançada diretamente nos cursos de água. O tratamento preliminar das águas usadas inclui o peneiramento e/ou gradeamento para reter os materiais sólidos e sedimentação do material em suspensão em tanques de decantação.

Os sistemas anaeróbios de tratamento de esgoto vêm sendo frequentemente utilizados com a finalidade de otimizar o processo de tratamento das águas residuárias, entre estes, um dos sistemas mais difundidos é o reator UASB (Upflow Anaerobic Sludge Blanket Reator) também conhecido como RAMAL (Reator Anaeróbio de Manta de

\footnotetext{
1Universidade Federal de Lavras/UFLA - Departamento de Engenharia - Cx. P. 3037 - 37.200-000 - Lavras, MG - vivian_galdino@hotmail.com 2Universidade Federal de Lavras/UFLA - Departamento de Engenharia - Lavras, MG

${ }^{3}$ Universidade Federal de Lavras/UFLA - Departamento de Engenharia - Lavras, MG

${ }^{4}$ Universidade Federal de Lavras/UFLA - Departamento de Ciência dos Alimentos - Lavras, MG

5 Universidade Federal de Lavras/UFLA - Departamento de Engenharia - Lavras, MG
} 
Lodo). Nesse reator, o processo ocorre em um tanque muitas vezes hermético, por meio do qual o fluxo ascendente de esgotos passa por meio de um leito denso e de elevada atividade (Campos, 1990).

O tratamento anaeróbio tem certa limitação quanto à eficiência, sendo necessário tratamento complementar ou pós-tratamento. A tecnologia de tratamento complementar de preferência deve seguir a mesma linha de não ser um sistema potencialmente consumidor de energia. Um dos sistemas que vem sendo implementados, visando a esse objetivo (polimento), é a combinação dos Reatores Anaeróbios de Manta de Lodo (UASB) com Filtros Anaeróbios (FA) (Chernicharo, 1997 e ABNT, 7229).

Filtros anaeróbios são caracterizados pela presença de um material de empacotamento estacionário, no qual os sólidos biológicos podem aderir ou ficar aderidos nos interstícios, conferindo ao sistema de tratamento uma capacidade de remoção complementar de matéria orgânica (Luiz, 2007).

Neste trabalho, dentre as alternativas viáveis de pós-tratamento, optou-se pelo reator anaeróbio híbrido (RAH), com uma conjugação de lodo disperso na parte inferior e com lodo de biofilme e intersticial na parte superior, utilizando para isso minifiltros compostos de argila expandida e seixo rolado.

Foram monitorados parâmetros físicos, químicos e biológicos no RAH, utilizado no pós-tratamento da água residuária do café (ARC) proveniente de dois reatores UASB concêntricos e fornecidas informações a respeito da investigação experimental realizada na instalação piloto. São apresentandos os resultados operacionais, físicos, químicos e biológicos, tanto da unidade de tratamento, como dos dois tipos de meio suporte (argila expandida e seixo rolado).

\section{MATERIAL E MÉTODOS}

O experimento foi realizado na Estação Piloto de Tratamento da Água Residuária de Café (Piloto-Café) localizada no Núcleo de Estudos em Cafeicultura - NECAF, do Departamento de Agricultura da Universidade Federal de Lavras - DAG/UFLA.

Para alimentação do sistema de tratamento, foi utilizado efluente do NECAF-UFLA, onde foram processados por via úmida, utilizando-se máquinas da marca Pinhalense ${ }^{\circledR}, 300.200$ litros de café da espécie Coffea arabica L., sendo que destes, 160.200 litros foram apenas lavados, 20.000 litros foram lavados e descascados e 120.000 passaram por todo o processo, sendo lavados, descascados e desmucilados.
O sistema piloto de tratamento das ARC era constituído por tratamento preliminar, com grades duplas, caixa de areia, unidades de tratamento secundário, lagoa de estabilização $\left(878 \mathrm{~m}^{3}\right)$, dois reatores UASB concêntricos trabalhando em série, tendo o Reator 1 (interno) $1.944 \mathrm{~L}$ e o Reator 2 (periférico) $2.490 \mathrm{~L}$, um reator anaeróbio híbrido com volume útil de $3.107 \mathrm{~L}$ funcionando para polimento (Figura 1), dois reatores aeróbios operando em batelada, com volume de $6.870 \mathrm{~L}$ cada, um leito de secagem de $12,0 \mathrm{~m}^{2}$ e seis reservatórios de efluentes. O sistema anaeróbio, constando dos dois reatores UASB e do RAH, possuíam, equalizador de pressão, cada um possuía filtro para remoção de $\mathrm{H}_{2} \mathrm{~S}$, medidor de biogás e queimador. Possuía ainda um sistema de bombeamento composto por três bombas submersas características e três bombas Nemo automatizadas.

Para o registro da temperatura do $\mathrm{RAH}$, foram medidos os valores de temperatura dos afluente e efluente por meio de aparelho portátil multifuncional da marca Schott, modelo Handlab LFl segundo o método eletrométrico 2320 B (APHA, 1998).

O sistema funcionou de maneira automatizada, por meio do controlador lógico programável - CLP, marca WEG, sendo controlado por válvulas solenóides e bóias instaladas na lagoa, reatores e reservatórios.

Durante o período de monitoramento, que compreendeu desde a inoculação do reator UASB e do RAH, (18 de agosto de 2006), até o desligamento geral do sistema (26 de janeiro de 2007), foram contabilizados 162 dias. Porém, para efeito de avaliação, foi considerado o período do dia 30 de agosto de 2006 até o dia 13 de janeiro de 2007, uma vez que o sistema ficou paralisado (do dia 19 a 29 de agosto de 2006) em razão da queima do estator de uma das bombas tipo Nemo, contabilizando, portanto, um período de 136 dias.

Nesse período foram avaliados três diferentes tempos de detenção hidráulica (TDH) em que o RAH foi submentido no intuito de se aumentar a carga orgânica biológica:

I) $30 / 08 / 2006$ a 16/11/2006 (dia 0 ao $\left.78^{\circ} \mathrm{dia}\right)-\mathrm{TDH}=$ 28,5 horas; 23,7 horas;

II) $17 / 11 / 2006$ a $06 / 12 / 2006\left(79^{\circ}\right.$ ao $\left.98^{\circ} \mathrm{dia}\right)-\mathrm{TDH}=$ 18,0 horas.

III) $07 / 12 / 2006$ a 13/01/2007 (99 ao $136^{\circ}$ dia $)-\mathrm{TDH}=$

As amostras foram coletadas em dois pontos do sistema, sendo o Ponto 1 o efluente do reator UASB periférico que era o afluente do RAH, e o Ponto 2, correspondente ao efluente do RAH. 


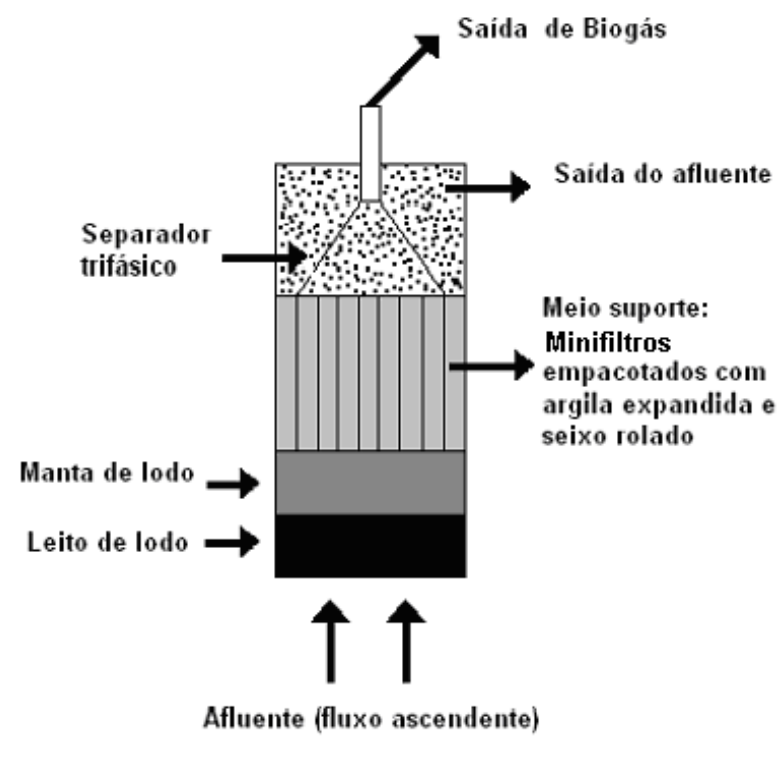

(a)

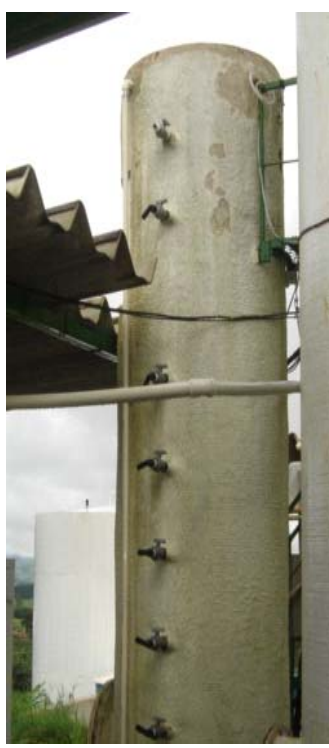

(b)

Figura 1 - Reator anaeróbio híbrido (RAH) localizado no NECAF/UFLA. (a) Desenho esquemático do funcionamento do reator anaeróbio híbrido (RAH); (b) vista parcial.

No RAH foram colocados cinquenta e quatro mini-filtros construídos em PVC, de $1 \mathrm{~m}$ de comprimento e $0,10 \mathrm{~m}$ de diâmetro. Quantidade essa definida pelo diâmetro do reator. Dentro de cada mini-filtro foram colocados dois materiais utilizados como meio suporte: argila expandida e seixo rolado. A densidade dos meios sendo igual a do líquido garantiu aos mini-filtros permanecerem verticais no líquido e na parte superior do reator. A argila expandida, além de ter superfície mais corrugada que o seixo rolado (quartzo), a fim de aumentar a aderência do biofilme, também era bem menos densa do que o seixo. Meio suporte leve, contribuiu para um menor peso sobre a estrutura do RAH. Tampas de PVC do tipo cap foram perfuradas e acopladas com anel de borracha na parte inferior e coladas na parte superior. Estabeleceu-se proporção argila expandida-seixo rolado de 27,6:1 (96,5 cm de argila expandida para 3,5 cm de seixo rolado). Tal proporção foi obtida por meio de testes em campo utilizando-se mini-filtros com diferentes proporções de argila expandida-seixo rolado, imersos em um tanque com água. Essa proporção permitiu que o a parte superior do mini-filtro ficasse sempre no nível do efluente dentro do reator.

O sistema foi monitorado diariamente, com acompanhamento da temperatura do efluente líquido, temperatura e umidade relativa do ambiente, análises de
pH, condutividade elétrica, salinidade e sólidos dissolvidos totais. Foram feitas, ainda, em intervalos pré-determinados, análises de DQO (demanda química de oxigênio), $\mathrm{DBO}_{5}$ (demanda bioquímica de oxigênio), ST (sólidos totais), STF (sólidos totais fixos), STV (sólidos totais voláteis), AT (alcalinidade total), AP (alcalinidade parcial) e AI (alcalinidade intermediária) e acidez total. Periodicamente, foram coletadas amostras do perfil dos reatores para determinação das concentrações de sólidos (ST, STF e STV), segundo metodologias propostas pelo Standard Methods for Examination of Water and Wastewater (APHA, 1998).

\section{RESULTADOS E DISCUSSÃO}

Verificou-se que o sistema de tratamento apresentou um bom tamponamento e não ocorreu risco de azedamento, provocado por baixo $\mathrm{pH}$ e elevada acidez.

Segundo Chernicharo (1997), na faixa de $\mathrm{pH}$ entre 6,0 e 7,5 a capacidade de tamponamento do sistema anaeróbio é quase que completamente dependente do sistema gás carbônico/alcalinidade.

Na Figura 2, mostra-se a condição homogênea e próxima à neutralidade dos valores de $\mathrm{pH}$ observados durante o primeiro TDH avaliado (28,8h), ficando em torno de 7,2; valor que em reatores anaeróbios é condição indispensável para um bom desempenho da atividade 
metanogênica. Essa fase do processo anaeróbio é considerada como a mais sensível dentre todas e, quando a condição de ambiência no reator não é adequada, ocorre um declínio imediato da taxa de produção de metano, com consequente diminuição no consumo de ácidos graxos, substrato principal das arqueas metanogênicas, acarretando em acúmulo destes no sistema, levando a uma queda do $\mathrm{pH}$ (Speece, 1996).

$\mathrm{O} \mathrm{pH}$, no decorrer do experimento aumentou, mesmo quando o sistema foi operado com cargas mais elevadas. Segundo Suzuki et al. (2002), na remoção de nutrientes é que o $\mathrm{pH}$ se torna um aliado, considerando que, sob condições alcalinas, $\mathrm{pH}$ em torno de 8 , ocorre a formação de cristais a partir de íons inicialmente solubilizados, como $\mathrm{PO}_{4}^{-3}, \mathrm{Mg}^{+2}$ e Ca ${ }^{+2}$ que, posteriormente, são retirados do meio líquido por decantação ou adesão.

De acordo com a classificação citada por Botelho (1999) e Campos (2000), tem-se que, para todas as fases analisadas, os efluentes pertenciam à Classe $\mathrm{C} 2$ quanto ao $\mathrm{pH}$, com restrição para utilização em irrigação de leve a moderada (pH entre 6,5 e 8,4 ), podendo ser usados sem quaisquer práticas especiais de controle.

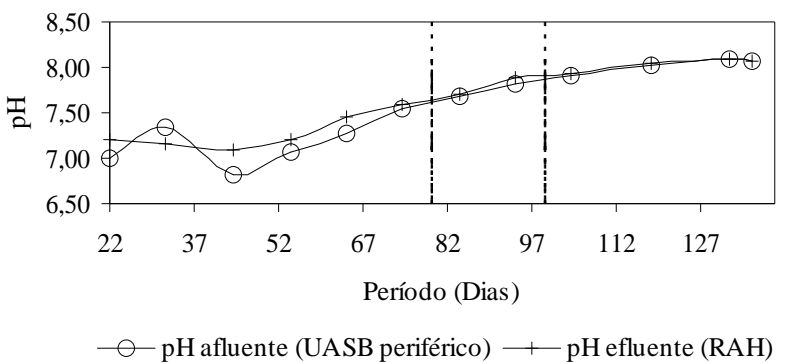

Figura 2 - Valores de $\mathrm{pH}$ afluente (UASB periférico) e efluente (RAH), em função do período operacional.
A acidez manteve índices mais baixos, demonstrando que o sistema operou em condições mais alcalinas em excelentes condições de tamponamento. O valor médio encontrado para cada TDH avaliado foi, respectivamente, 64,96; 43,23 e 29,31 $\mathrm{mg} \mathrm{L}^{-1}$ (Figura 3).

Na Figura 4, são apresentados os valores médios de temperatura registrados na unidade anterior ao RAH (UASB periférico), e no RAH, coletadas ao longo do experimento cujas curvas submetidas entre si, ao teste de correlação por meio de planilha eletrônica Excel®, apresentaram o valor de 0,98 , demonstrando haver elevada correlação. A média da temperatura afluente e efluente para cada TDH avaliado foi de $23{ }^{\circ} \mathrm{C} ; 23,5{ }^{\circ} \mathrm{C}$ e $24,8^{\circ} \mathrm{C}$, respectivamente, situando-se entre as faixas ideais para as bactérias mesofílicas.

As avaliações de eficiência de remoção de material orgânico foram feitas em função do parâmetro DQOtot. Porém, como forma de avaliar a biodegradabilidade do efluente líquido utilizado, foram feitas caracterizações esporádicas da $\mathrm{DBO}_{5}$, as quais forneceram os seguintes valores médios de eficiência para $\mathrm{DBO}_{5}$ e DQOtot:

-Para TDH $=28,5$ horas: $\mathrm{E}-\mathrm{RAH}=37,55 \%$ e $18 \%$;

-Para TDH $=23,7$ horas: $\mathrm{E}-\mathrm{RAH}=-6,95 \%$ e $5,5 \%$;

-Para TDH $=18,0$ horas: E-RAH $=-8,79 \%$ e 3,7\%.

As eficiências negativas mostram haver endogenia e, consequentemente, wash out nas duas últimas fases avaliadas.

O RAH foi operado de forma bastante estável durante o primeiro TDH e com eficiência baixa na remoção de $\mathrm{DBO}_{5}$, em razão, principalmente, da remoção prévia da carga da água residuária utilizada que, em média, apresentou concentração afluente ao RAH de 17,6 mg DBO $\mathrm{L}^{-1}$ (entrada do reator). Inicialmente, o reator operou com

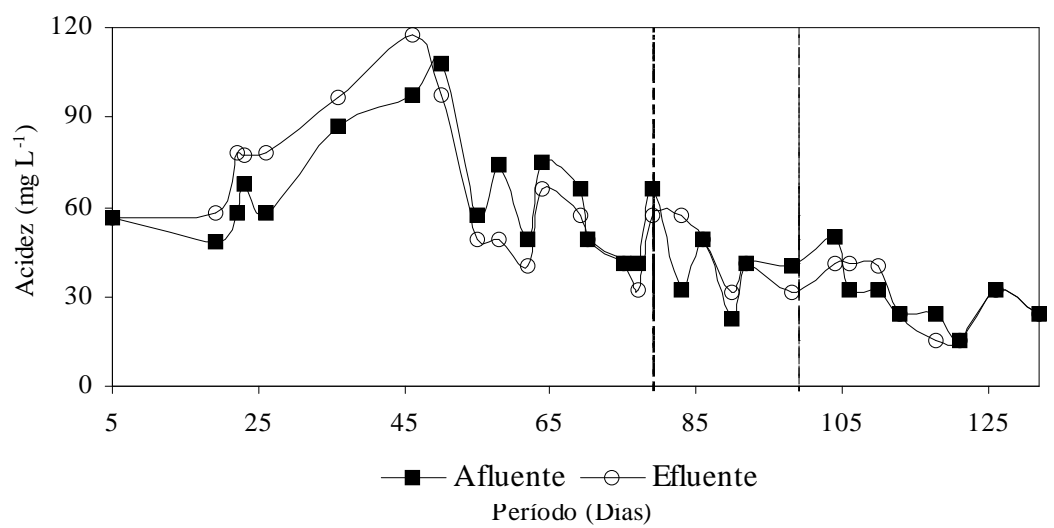

Figura 3 - Gráfico do comportamento da acidez no RAH. 
afluente de $39 \mathrm{mg} \mathrm{DBO}_{5} \mathrm{~L}^{-1}$ e efluente de $23 \mathrm{mg} \mathrm{DBO}_{5} \mathrm{~L}^{-1}$, no final do experimento a $\mathrm{DBO}_{5}$ afluente era de apenas 6 mg DBO $\mathrm{L}^{-1}$ e efluente de 7,9 mg $\mathrm{DBO}_{5} \mathrm{~L}^{-1}$, em razão da elevada autodepuração ocorrida na lagoa (Silva, 2007), remoção nas várias unidades anteriores incluindo os tanques de armazenamento, a recirculação do efluente novamente para a lagoa de estabilização. Na fase final, observou-se que houve, provavelmente, carreamento de sólidos.

Lourenço (2006), trabalhando em sistema de bancada, encontrou para o filtro anaeróbio uma remoção de $\mathrm{DBO}_{5}$ de $49 \%$. Todavia, o efluente deste era bem mais concentrado.

O RAH, em média, apresentou concentração afluente de 484,43 $\pm 264 ; 168,56 \pm 29$ e 92,70 $\pm 30 \mathrm{mg} \mathrm{DQO} \mathrm{tot} \mathrm{L}^{-1}$ (entrada do RAH) e efluente de $344,51 \pm 141 ; 159,33 \pm 32$ e $90,75 \pm 34 \mathrm{mg}$ $\mathrm{DQO}_{\text {tot }} \mathrm{L}^{-1}$ (saída do RAH) para os TDH de 28,5; 23,7 e 18,0 horas, respectivamente (Figura 4). Como para o primeiro TDH o período de tempo foi maior, observa-se, neste, maior valor de desvio padrão. Inicialmente, o reator operou com afluente com $828 \mathrm{mg}$ DQO $_{\text {tot }} \mathrm{L}^{-1}$ e efluente com $306 \mathrm{mg} \mathrm{DQO}_{\text {tot }}$ $\mathrm{L}^{-1}$. No final do experimento, a $\mathrm{DQO}_{\text {tot }}$ afluente foi de apenas 64,67 mg DQO $\mathrm{mot} \mathrm{L}^{-1}$ e efluente de $80 \mathrm{mg} \mathrm{DQO}_{\text {tot }} \mathrm{L}^{-1}$, mostrando que no último estágio estava ocorrendo endogenia com saída de biomassa do RAH (Figura 5).

Ainda que se aumentasse a vazão do sistema, decorrente da remoção prévia da carga do efluente, o reator operaria com cargas biológicas descrescentes como observado comparando-se os valores acima apresentados e observando a Tabela 1 .

No caso de tratamento biológico a concentração de fósforo deve alcançar níveis compatíveis ao bom desempenho dos processos bioquímicos de oxidação da matéria orgânica, e a necessidade de fósforo para a remoção da matéria orgânica biodegradável deve atender à relação DBO/P < 100 (Braile \& Cavalcanti, 1993).

A maior concentração de $\mathrm{P}_{\text {tot, }}$ observada neste trabalho, ocorreu no primeiro TDH atingindo $0,4 \mathrm{mg} . \mathrm{L}^{-1}$ no afluente do RAH. $\mathrm{O}$ valor do efluente para o último TDH foi de $0,11 \mathrm{mg} \mathrm{L}^{-1}$, valor abaixo da concentração máxima permitida pela legislação, que é de $0,15 \mathrm{mg} \mathrm{L}^{-1}$, para águas doces da classe 3 (CONAMA, 2005).

Com relação ao nitrogênio, ao longo do monitoramento, foram observados valores bem próximos para os dois pontos da coleta, como mostrado na Figura 52 , evidenciando que a remoção foi muito baixa e que a quantidade de nitrogênio era estável no afluente e no efluente ao RAH. As análises de nitrogênio foram realizadas após a terceira partida, quando o sistema já funcionava, normalmente, as concentrações de matéria orgânica eram baixas e a biomassa ativa nos reatores era pequena (Tabela 2).

Relacionando-se as variáveis DQO, $\mathrm{N}$ e $\mathrm{P}$, verificouse alta concentração de $\mathrm{DQO}$ e de $\mathrm{N}$ em relação ao $\mathrm{P}$,

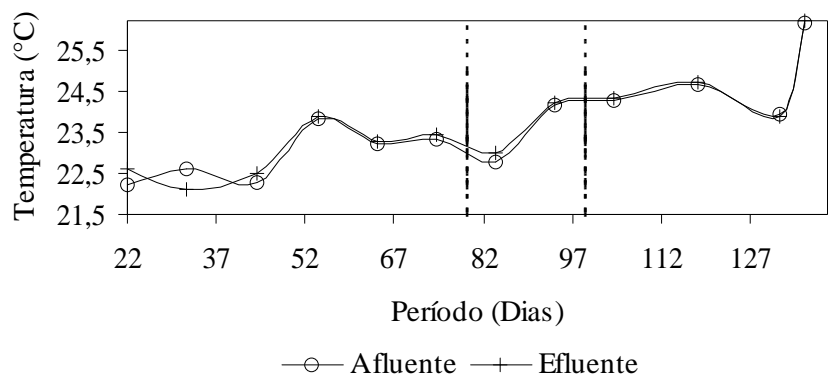

Figura 4 - Temperaturas médias do afluente e efluente do RAH, durante as etapas do tratamento.

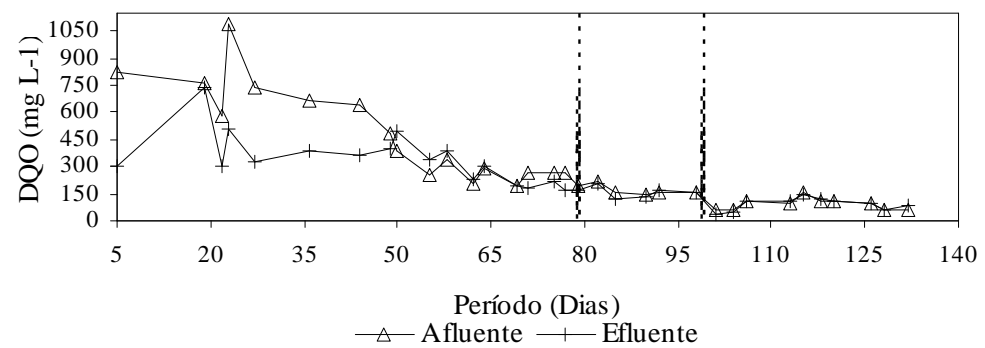

Figura 5 - Valor de DQO afluente e efluente do RAH durante as etapas do tratamento. 
Tabela 1 - Parâmetros analisados aos 79 e aos 99 dias de monitoramento do sistema piloto de tratamento de água residuária do café, localizado no NECAF/UFLA.

\begin{tabular}{|c|c|c|}
\hline Parâmetros & $79^{\circ}$ dia & $99^{\circ}$ dia \\
\hline Rotação B3 (rpm) & 1.200 & 1.600 \\
\hline $\mathrm{Q}_{\mathrm{B} 3}\left(\mathrm{~m}^{3} \mathrm{~d}^{-1}\right)$ & 3,14 & 4,13 \\
\hline $\mathrm{DBO}_{5} \mathrm{RAH}\left(\mathrm{mg} \cdot \mathrm{L}^{-1}\right)$ & 31 & 14 \\
\hline DQO RAH(mg. $\left.\mathrm{L}^{-1}\right)$ & 195 & 58 \\
\hline COB RAH $\left(\mathrm{kg} \mathrm{DBO}_{5} \mathrm{kgSVT}^{-1} \cdot \mathrm{d}^{-1}\right)$ & 0,0014587 & 0,00099 \\
\hline TDH R2 (hora) & 19 & 10,6 \\
\hline TDH RAH (hora) & 23,73 & 18,03 \\
\hline $\mathrm{COV}_{\mathrm{DBO} 5} \mathrm{RAH}\left(\mathrm{kg} \mathrm{DBO}_{5} \mathrm{~m}^{-3} \mathrm{~d}^{-1}\right)$ & 0,032 & 0,018 \\
\hline $\mathrm{COV}_{\mathrm{DQO}} \mathrm{RAH}\left(\mathrm{kg} \mathrm{DBO}_{5} \mathrm{~m}^{-3} \mathrm{~d}^{-1}\right)$ & 0,199 & 0,077 \\
\hline $\mathrm{X}_{\mathrm{vt}} \mathrm{RAH}(\mathrm{kgSVT})$ & 66,77 & 58,40 \\
\hline
\end{tabular}

evidenciando que o sistema possuía uma biomassa com baixo coeficiente de produção celular e que os nutrientes, presentes no esgoto, principalmente o fósforo, talvez não estivessem numa forma disponível para as bactérias (Tabela 3).

Tabela 2 - Concentração de P-tot e NTK afluente e efluente do RAH observada durante o monitoramento do sistema piloto de tratamento da água residuária do café, localizado no NECAF/UFLA.

\begin{tabular}{ccccc}
\hline & \multicolumn{2}{c}{ NTK $\left(\mathrm{mg} . \mathrm{L}^{-1}\right)$} & \multicolumn{2}{c}{ P-tot $\left(\mathrm{mg.L} \mathrm{L}^{-1}\right)$} \\
\hline & Afluente & Efluente & Afluente & Efluente \\
\hline Fase I & 70 & 75 & 0,25 & 0,16 \\
Fase II & 35 & 35 & 0,22 & 0,16 \\
Fase III & 55 & 53 & 0,12 & 0,11 \\
\hline
\end{tabular}

Tabela 3 - Relação $\mathrm{DBO}_{5} / \mathrm{P}$ verificada no afluente e efluente do RAH, durante o monitoramento do sistema piloto de tratamento de água residuária do café localizado no NECAF/UFLA.

\begin{tabular}{cc}
\hline RAH & $\mathrm{DBO}_{5} / \mathrm{P}$ \\
\hline Afluente & 1732 \\
Efluente & 1733 \\
\hline
\end{tabular}

A diminuição da concentração de sólidos totais nos reatores, durante o período de monitoramento do sistema, indica decréscimo da biomassa, prejudicando extremamente o processo de digestão anaeróbia e a produção de biogás, uma vez que os sólidos representam a presença de matéria orgânica e inorgânica em um efluente.
O lodo inoculado no RAH, sofreu sedimentação e liquefação, tornando-se, ao final do monitoramento, um lodo ralo, sedimentado, e com baixa concentração de sólidos voláteis, justificado pelas baixas cargas orgânicas aplicadas a ele, pelas paralisações do sistema e, principalmente, em razão da baixa concentração do afluente, mostrando que o efluente recebido não foi suficiente para formar uma camada de lodo densa, com alta atividade microbiana, e biofilmes mais espessos (Tabela 4).

No início do monitoramento, observa-se um aumento na condutividade elétrica, que a partir do segundo TDH avaliado, começa a decair. Os valores médios para o efluente em cada TDH avaliado foram, respectivamente, 1,$2 ; 1,3$ e 1,0 dS.m ${ }^{-1}$. No terceiro TDH os valores afluente e efluente encontrados mantiveram-se próximos e constantes. Para os três TDH avaliados as concentrações de SDT ficaram bem abaixo de $2.000 \mathrm{mg} . \mathrm{L}^{-1}$. Comparados com a classificação citada por Botelho (1999) e Campos (2000), tem-se que os efluentes analisados pertencem à Classe C2 quanto à salinização, com salinidade leve a moderada (CE entre 0,70 e 3,0 dS m$~^{-1}$ e SDT de 450 a 2000 $\left.\mathrm{mg} \mathrm{L}^{-1}\right)$, podendo ser usados para irrigação da maioria das culturas e solos, sem práticas especiais de controle de salinidade, conferindo ao efluente grau de restrição para uso em irrigação de leve a moderado.

A Razão de Adsorção de Sódio (RAS), usada para predizer os possíveis problemas de infiltração e impermeabilização do solo, ficou entre 0,08 e 0,11 , sendo considerados baixos. Analisada conjuntamente com a $\mathrm{CE}$ do efluente, para se poder avaliar corretamente o efeito da água de irrigação na redução da capacidade de infiltração de um solo, essa combinação varia entre 0 e 3 e CE>0,7 dS $\mathrm{m}^{-1}$ (Salassier et al., 2005), ficando dentro da faixa encontrada 
Tabela 4 - Parâmetros observados na inoculação e nas três partidas realizadas no sistema piloto de tratamento de água residuária do café, localizado no NECAF/UFLA.

\begin{tabular}{|c|c|c|c|c|}
\hline Parâmetro & Inoculação & $1^{\mathrm{a}}$ partida & $2^{\mathrm{a}}$ partida & $3^{\mathrm{a}}$ partida \\
\hline DQO (mg.L $\left.{ }^{-1}\right)$ - Afluente do RAH & - & 828 & 665 & 645 \\
\hline $\mathrm{DBO}_{5}\left(\mathrm{mg} . \mathrm{L}^{-1}\right)-$ Efluente do RAH & - & 310 & 280 & 380 \\
\hline $\mathrm{COB}\left(\mathrm{kg} \mathrm{DBO}_{5} \mathrm{kgSVT}^{-1} \mathrm{~d}^{-1}\right)$ & - & 0,0156 & 0,0103 & 0,01213 \\
\hline $\mathrm{X}_{\mathrm{vt}} \mathrm{RAH}(\mathrm{kgSVT})$ & - & 51,926 & 71,25 & 82,09 \\
\hline TDH R2 (hora) & - & 22,4 & 22,4 & 22,4 \\
\hline TDH RAH (hora) & - & 28,5 & 28,5 & 28,5 \\
\hline$Q_{\text {afluente do RAH }}\left(\mathrm{m}^{3} \mathrm{~d}^{-1}\right)$ & - & 2,62 & 2,62 & 2,62 \\
\hline $\mathrm{COV}_{\mathrm{DBO}} \mathrm{RAH}\left(\mathrm{kg} \mathrm{DBO}_{5} \mathrm{~m}^{-3} \mathrm{~d}^{-1}\right)$ & - & 0,26 & 0,236 & 0,32 \\
\hline $\mathrm{COV}_{\mathrm{DQO}} \mathrm{RAH}\left(\mathrm{kg} \mathrm{DQO}_{5} \mathrm{~m}^{-3} \mathrm{~d}^{-1}\right)$ & - & 0,70 & 0,56 & 0,54 \\
\hline $\mathrm{pH}$ & 5,34 & 7,34 & 7,06 & 6,73 \\
\hline Temperatura ${ }_{\text {afluente }}\left({ }^{\circ} \mathrm{C}\right)$ & 19,05 & 19,06 & 22,3 & 22,6 \\
\hline $\mathrm{CE} \operatorname{RAH}\left(\mathrm{dS} \mathrm{m}{ }^{-1}\right)$ & 0,63 & 0,83 & 0,82 & 1,15 \\
\hline SDT RAH $\left(m g . L^{-1}\right)$ & 507 & 645 & 640 & 903 \\
\hline
\end{tabular}

durante o monitoramento. Esses valores indicam que o efluente tratado não apresenta grau de restrição ao uso para irrigação.

\section{CONCLUSÕES}

O período em que se desenvolveu o experimento dificultou a análise da maior eficiência que o reator anaeróbio atingiria. As unidades de tratamento anteriores, fizeram com que a baixa carga diminuísse a eficiência do RAH.

A baixa carga afluente e escassez de fósforo causou endogenia e, consequentemente, baixa produção de lodo, não se observando crescimento da biomassa, floculação ou granulação da mesma.

Houve estabilização do sistema, com equilíbrio dos parâmetros físico-químicos para os pontos analisados considerando o efluente do Reator UASB periférico e o efluente do RAH, para baixas cargas de operação.

O efluente final analisado não apresentou riscos de salinidade ou de sodificação, podendo ser reutilizado, sem restrições para irrigação da maioria das culturas ou solos.

Verificou-se que o RAH apresentou eficiência bem abaixo do esperado, pelos motivos já expostos anteriormente, todavia, para maiores cargas orgânicas, e observando criteriosamente a proporção de DQO:N:P, acredita-se que a referida unidade deverá apresentar desempenho bem superior quanto a eficiência na remoção de material orgânico e inorgânico, utilizando tanto da manta de lodo (lodo disperso), como do biofilme (lodo aderido) e, ainda, o lodo intersticial, formado nos vazios do meio suporte.

\section{AGRADECIMENTOS}

Ao Conselho Nacional de Pesquisa (CNPq), pela concessão da bolsa de estudos.

À Fundação de Amparo a Pesquisa do Estado de Minas Gerais (FAPEMIG), pelo financiamento do projeto intitulado "Monitoramento de parâmetros físicos, químicos e biológicos em um reator anaeróbio híbrido (RAH) em escala piloto tratando água residuária do café produzido por via úmida”, dentro do programa de Apoio ao Desenvolvimento Tecnológico para Inovação Agroindustrial (EDT n 013-23000-01).

\section{REFERÊNCIAS BIBLIOGRÁFICAS}

AMERICAN PUBLIC HEALTH ASSOCIATION. Standard methods for the examination of water and wastewater. Washington, 1998.

ASSOCIAÇÃO BRASILEIRA DE NORMAS TÉCNICAS - ABNT. NBR 6467 - Agregados: determinação do inchamento do agregado miúdo, especificação. Rio de Janeiro, 1987. 5 p.

BOTELHO, C. G. Qualidade da água para irrigação. Lavras: UFLA/FAEPE, 1999. v.I, 96p.

BRAILE, P. M.; CAVALCANTI, E. W. A. Manual de tratamento de águas residuárias industriais. São Paulo: CETESB, 1993.764 p. 
CAMPOS, C. M. M. Physical aspects affecting granulations in UASB Reactors. 1990. 459 p. Thesis (PhD) - University of Newcastle upon Tyne, Newcastle.

CAMPOS, C. M. M. Qualidade da água para irrigação. Lavras: UFLA/FAEPE, 2000. v. 2, 121 p. (Curso de pós Graduação "Lato Sensu": Sistemas pressurizados de irrigação).

CHERNICHARO, C. A. L. Reatores anaeróbios. Belo Horizonte: UFMG/DESA, 1997. v. 5, 246 p.

LOURENÇO, A.M.P. Desempenho de um sistema composto de reator UASB, filtro anaeróbio e lagoa aerada facultativa para o tratamento das águas residuárias da suinocultura. 2006. 129 p. Dissertação (Mestrado em Engenharia Agrícola) - Universidade Federal de Lavras, Lavras, MG.

LUIZ, F. A. R. Desempenho de reatores anaeróbios de leito fixo no tratamento de águas residuárias da lavagem e descascamento/despolpa dos frutos do cafeeiro. 2007. 132 p. Dissertação (Mestrado em Engenharia Agrícola) Universidade Federal de Viçosa, Viçosa, MG.

SALASSIER, B.; SOARES, A. A.; MANTOVANI, E. C. Manual de irrigação. 7. ed. Viçosa: Ed. UFV, 2005. 611 p.

SPEECE, R. E. Anaerobic biotechnology for industrial wastewaters. Vanderbilt University, 1996. 394 p.

SILVA, J. F. Monitoramento de um sistema piloto no tratamento de água residuária do café produzido por via úmida. 2007. 133 p. Dissertação (Mestrado em Engenharia Agrícola) - Universidade Federal de Lavras, Lavras, MG.

SUZUKI, K.; TANAKA, Y.; OSADA, T.; WAKI, M.. Removal of phosphate, magnesium and calcium from swine wastewater through crystallization enhanced by aeration. Water Research, Oxford, v. 36, n. 12, p. 29912998, July 2002. 